\title{
Extrarenal Rhabdoid Tumor
}

National Cancer Institute

\section{Source}

National Cancer Institute. Extrarenal Rhabdoid Tumor. NCI Thesaurus. Code C6586.

A rhabdoid tumor which arises in the soft tissues. It occurs in infants and children and may be associated with loss of chromosome 22 . It is characterized by the presence of cells with a large eccentric nucleus, prominent nucleolus, and abundant cytoplasm. 